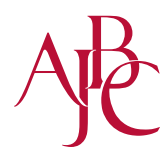

\title{
Effects of Visual Images of Low-cost Cosmetics on Consumer Types and their Behaviors
}

\author{
Sang Eun Lee \\ Department of Beauty and Arts, Suwon Women's University, Suwon-si, Gyeonggi-do, Korea
}

Corresponding author: Sang Eun Lee, Department of Beauty and Arts, Suwon Women's University, 72 Onjeong-ro, Gwonseon-gu, Suwon-si, Gyeonggi-do 16632, Korea

Tel.: +82 312908374

Email: make-up1004@swc.ac.kr

Received February 15, 2016

Revised March 23, 2016

Accepted March 23, 2016

Published March 30, 2016

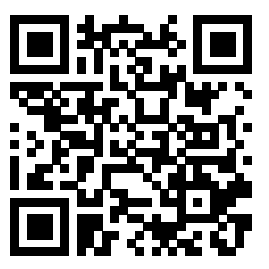

\begin{abstract}
Purpose: This study attempted to unveil differences in the effects of the visual image parameters of low-cost cosmetics on consumer type and buying behavior. Methods: Adult women who used low-cost cosmetics before were recruited through convenience sampling. For a validity test, factor analysis, one-way ANOVA, Scheffe's multiple range test and multiple regression were performed. Results: In terms of visual images, the following five factors were derived: logo color, product container design, brand logo, cosmetics poster and display. Regarding a consumer type, trendy, economic and planned types were found. The logo color and display revealed a significant difference depending on the time and place of purchase. A significant influence was partially found according to consumer type. Conclusion: The study results propose the development of a marketing differentiation strategy using unique visual images in addition to the improvement of standardized product quality and price competitiveness, understanding the fact that the visual images of low-price cosmetics have a positive effect on consumer type and buying behavior.
\end{abstract}

Keywords: Visual image, Low-cost cosmetics, Consumer types, Buying behavior, Cosmetic industry

\section{Introduction}

국내의 화장품 산업은 1960 년대에 이르러 본격적인 산업으 로 규모를 갖추게 되었고, 이후 방문판매, 화장품 전문점을 거 쳐 1990년대에 이르러 마트, 체인점, 홈쇼핑, 인터넷 쇼핑몰 등으로 화장품 유통경로가 확대되면서 화장품 시장이 더욱 성 장하였다. 현재의 화장품 시장은 다각화된 유통채널로 구매가 쉽고 편리해졌으며, 다양한 소비자들의 욕구에 부응하기 위하 여 빠르게 변화하고 있다(Lee et al., 2012).

그 중에서도 2003년 화장품 제조회사인 (주) Able C\&C 가 국내 저가화장품 브랜드 숍 '미샤'를 선도적으로 오픈하여 유 통업계에 뛰어들면서, 유통 구조의 개선 및 제품의 질 향상, 다양한 이벤트 제공, 체험 공간 등을 통하여 소비자와 브랜 드 간의 긍정적인 유대관계를 형성하여 브랜드 이미지를 구축 하는 화장품 시판시장의 새로운 트렌드를 창출하였다(Lee \& Hwang, 2010).

미샤 런칭에 이어 더페이스샵, 뷰티크레딧, 토니모리, 스
킨푸드, 에뛰드 등은 저가화장품 초고속 성공에 가담하면서 과거 화장품은 사치품이고 비싼 화장품이 좋다라는 소비자 들의 고정관념을 탈피하였고, 매출이 증가하는 등 영업성과 를 거두고 있다(Ahn \& Shin, 2012). 또한 기초, 색조, 헤 어, 네일, 바디 등 다양한 구성으로 여성제품뿐만 아니라 남 성, 어린이 등 다양한 소비자의 욕구를 파악하고 좀 더 세분 화된 구성으로 활발한 성장을 이루었다(Kim, 2011). 저가 화장품 브랜드들은 기업 간 제품의 물리적 기술 격차가 좁혀 지고 있는 상황에서 낮은 품질의 제품으로만 소비자에게 요 구하는 것이 아니라, 제품의 특성이나 기술수준에 대한 차별 적 우위를 갖는 것도 중요하다. 이러한 제품으로부터 형성된 이미지가 '소비자에게 어떠한 의미를 전달해주는가'하는 측 면에서의 총체적 관리(Management)가 기업의 생존과 지속 적인 성장을 위한 가장 핵심적인 요인이라고 할 수 있다. 실 제로 저가라는 가격경쟁력 보다는 브랜드마다 각각 다른 브 랜드 컨셉을 채택하고 컨셉에 맞춘 제품을 출시함으로써 고 객몰이에 나서고 있다(Chung \& Kim, 2009). 특히 화장품 
은 기능과 가격보다는 해당 브랜드이미지와, 제품의 디스플 레이 이미지 등 시각적 이미지 연출이 브랜드 이미지에 영향 을 미치게 되고 감성마케팅 중 시각적 요소는 화장품 브랜드 의 이미지를 비교적 짧은 순간에 인식하게 하고 소비자를 자 극하여 구매욕구와 구매행동으로 이어지게 하는 중요한 요 소이다.

그러나 화장품은 질적 차이가 뚜렷하게 인식이 되지 않는 특 징을 갖고 있고 인터넷과 통신의 발달로 일반 소비자들도 전문 적인 정보들을 손쉽게 접할 수 있게 되면서 가격과 품질에 대한 신뢰를 잃어가고 있는 실정이다. 이와 같이 똑똑한 소비자들이 많아지고 있는 추세와 함께 저렴한 가격과 우수한 품질, 구입의 용이성을 갖고 있는 저가화장품 시장은 매우 경쟁력 있는 시장 임이 틀림없다(Kim, 2011).

지금까지 선행된 국내 저가화장품 관련 연구들을 살펴보 면 만족도와 충성도에 관한 연구(Kim \& Roh, 2008; Chung $\& \mathrm{Kim}, 2009$; Ryu, 2008), 구매행동과 사용실태에 관한 연 구(Kim, 2011; Hyun \& Choo, 2005; Song, 2015), 저가 화장품 패키지 디자인 특성으로 본 연구(Han et al., 2012 ; Lee \& Shin, 2012), 아이덴티티와 컬러 활용 사례(Lee et al., 2012) 등의 연구가 있었다. 이와 같이 저가화장품의 만 족도와 충성도 구매행동 각각의 관계를 분석한 연구는 많았 으나 저가화장품 브랜드의 포화 상태에서 브랜드 차별화를 위한 시각적 이미지에 따라 소비자유형을 세분화 하고 세분 화된 소비자유형과 구매행동의 차이를 밝힌 연구는 매우 부 족한 실정이다.

따라서 본 연구는 저가화장품의 시각적 이미지 매개변수 가 소비자유형과 구매행동에 미치는 특성 차이를 밝히고자 한다. 즉 저가화장품의 시각적 이미지에 나타난 복합적인 특성이 구체적으로 소비자유형과 화장품 구매과정에서 어 떻게 작용하는지를 파악하고 시장 세분화의 기초자료를 제 공하여 판매전략 수립 기틀마련에 도움이 될 것이라고 사료 된다.

\section{Methods}

\section{1. 연구대상 및 자료수집}

본 연구 대상의 표집은 2015년 07월 20일부터 08월 12일 까지 수도권 및 경기도 지역에서 저가화장품을 사용한 경험이 있는 성 인여성 10 대부터 50 대까지의 연령대를 대상으로 편의 표집하였다.

총 250 명에게 설문을 배포하여 자기기입식으로 작성하였으 며 그 중 응답이 불충분한 9 부를 제외한 설문지 총 241 부를 본 연구의 자료로 사용하였다.

\section{2. 측정항목 및 내용}

본 연구에 사용된 문항은 총 24 문항으로 인구통계학적 특성, 시각적 이미지, 소비자유형, 구매행동으로 구성되었으며 설문 지의 측정항목구성과 출처는 다음과 같다(Table 1).

\section{3. 분석 방법}

본 연구의 실증분석은 모두 유의수준 $5 \%$ 에서 검증하였으며, 통계처리는 SPSS WIN 18.0 프로그램을 사용하여 분석하였 다.

1) 일반적 특성과 화장품 구매행동 특성을 알아보기 위하 여 빈도분석(Frequency Analysis)을 실시하였다.

2) 화장품의 시각적 이미지, 화장품 소비자유형에 대한 문 항들의 타당도 검증을 위하여 요인분석을 실시하였다.

3) 화장품의 시각적 이미지, 화장품 소비자유형에 대한 신 뢰도는 Cronbach's $\alpha$ 의 계수로 판단하였다.

4) 저가화장품의 시각적 이미지가 구매행동에 미치는 영 향을 알아보기 위하여 일원변량분석(one-way ANOVA) 을 실시하였으며, Scheffe의 다중범위 검정(Scheffe's multiple range test)을 통하여 $\mathrm{p}<.05$ 에서 유의한 차이를 검정하였다.

5) 화장품의 시각적 이미지가 화장품 소비자유형에 미치 는 영향을 알아보기 위하여 다중회귀분석을 실시하였다.

Table 1. Configuration of a questionnaire

\begin{tabular}{llcl}
\hline Research variables & Scales & No. of questions & Quotation \& applied data \\
\hline Demographic features & Nominal scale & 3 & Organization of researchers \\
Purchasing behaviors & Nominal scale & 3 & - Oh Eunyeong (2005) \\
& & & - Song Yeongju (2011) \\
Consumer type & 5-point likert scale & 13 & - Mun Hyeon (2010) \\
& & & - Oh Eunyeong (2011) \\
Visual image & 5-point likert scale & 15 & - Yi Sinae (2010) \\
& & & - Yi Ujeong (2015) \\
\hline
\end{tabular}




\section{Results and Discussion}

\section{1. 일반적 특성}

연구대상자의 일반적 특성을 살펴보면 연령은 '41-50세 이하'가 $30.3 \%, 21-30$ 세 이하'가 $29.9 \%, 31-40$ 세 이하'가 $24.9 \%$, '20세 이하'가 $14.9 \%$ 순이었다. 직업은 ‘학생’이 $24.9 \%$ 로 가장 많았고, '기타' $22.0 \%$, '회사원' $17.4 \%$, '가정주부'와 '판매 서비스업'이 각각 $16.2 \%$ 순으로 조사되었으며 용돈은
‘40만원 이상' 39.0\%, ‘20-30만원 미만’과 ‘30-40만원 미만’이 각각 $16.6 \%, ' 10-20$ 만원 미만' $14.1 \%$, '10만원 미만' $13.7 \%$ 순으로 조사되었다(Table 2). 저가화장품 구매행동을 특성에서 저가화장품을 구입한 장소는 화장품 전문매장 $29.9 \%$, 저가 브 랜드샵 $22.8 \%$, 백화점 $17.0 \%$ 의 순으로 나타났으며, 가장 많이 구입하는 제품은 색조 화장품이 $44.0 \%$ 로 가장 많았으며 최근 저가화장품 구입 시기로는 '최근 1 개월 이내’ $28.6 \%$, ‘최근 3 개 월 이내' $28.2 \%$, '기타' $20.3 \%$ 순으로 나타났다(Table 3).

Table 2. General features

\begin{tabular}{|c|c|c|c|}
\hline & & Frequency $(\mathrm{N})$ & Percentage (\%) \\
\hline \multirow{5}{*}{ Age } & Below 20 & 36 & 14.9 \\
\hline & $21-30$ & 72 & 29.9 \\
\hline & $31-40$ & 60 & 24.9 \\
\hline & $41-50$ & 73 & 30.3 \\
\hline & Housewives & 39 & 16.2 \\
\hline \multirow{4}{*}{ Vocation } & Office workers & 42 & 17.4 \\
\hline & Government employees & 8 & 3.3 \\
\hline & Students & 60 & 24.9 \\
\hline & Sales people & 39 & 16.2 \\
\hline \multirow{7}{*}{ Monthly pocket money } & Miscellaneous & 53 & 22.0 \\
\hline & Below 100,000 & 33 & 13.7 \\
\hline & $100,000-200,000$ & 34 & 14.1 \\
\hline & $200,000-300,000$ & 40 & 16.6 \\
\hline & $300,000-400,000$ & 40 & 16.6 \\
\hline & Over 400,000 & 94 & 39.0 \\
\hline & Total & 241 & 100.0 \\
\hline
\end{tabular}

Table 3. Features of purchasing behaviors of low-cost cosmetics

\begin{tabular}{|c|c|c|c|}
\hline & & Frequency $(\mathrm{N})$ & Percentage (\%) \\
\hline \multirow{6}{*}{ Place of purchasing low-cost cosmetics } & Department stores & 41 & 17.0 \\
\hline & Cosmetic stores & 72 & 29.9 \\
\hline & Discount stores & 40 & 16.6 \\
\hline & Home shopping \& internet & 33 & 13.6 \\
\hline & Low-cost cosmetics brand shops & 55 & 22.8 \\
\hline & Makeup cosmetics (a) & 106 & 44.0 \\
\hline \multirow{2}{*}{ Low-cost cosmetics purchased } & Basic care cosmetics (b) & 71 & 29.5 \\
\hline & Body cosmetics (c) & 41 & 17.1 \\
\hline \multirow{6}{*}{ Time when purchasing low-cost cosmetics } & Nail cosmetics $(d)$ & 23 & 9.5 \\
\hline & In recent 1 month & 69 & 28.6 \\
\hline & In recent 3 months & 68 & 28.2 \\
\hline & In recent 6 months & 30 & 12.4 \\
\hline & In recent 1 year & 25 & 10.4 \\
\hline & Others & 49 & 20.3 \\
\hline \multicolumn{2}{|c|}{ Total } & 241 & 100.0 \\
\hline
\end{tabular}




\section{2. 저가화장품 시각적 이미지 요인 분석}

저가화장품 시각적 이미지 요소에 대한 타당도 검증을 위 해서 주성분분석(Principal Component Analysis)방법과 직교회전방법인 VARIMAX를 사용하여 요인분석(Factor Analysis)을 실시하였다. 그 결과 $\mathrm{KMO}$ 값이 0.846으로 변 수 쌍들의 상관관계가 다른 변수에 의해 잘 설명되는 것으 로 판단할 수 있으며, 요인분석의 적합성 여부를 나타내는 Bartlett의 구형성 검정치(Test of Sphericity)는 근사 카이 제곱값이 1878.497로 유의수준이 .000으로 나타나 요인분 석 사용이 적합하다는 것을 알 수 있다. 요인을 추출하기 위 한 방법으로는 각 요인이 기존변수의 정보를 어느 정도 설 명하는지를 나타내는 고유값(eigen-value)을 이용하여, 고 유값이 1.0 이상인 요인에 한하며 요인적재량이 0.4 이상인 항목들을 기준으로 설정하여 요인수를 5 개로 결정하였다. 그 결과 요인 1 은 고유값이 3.608 , 설명비가 $24.05 \%$ 로 나 타났으며 '디스플레이' 로 명명하였으며, 요인 2는 고유값이 2.358 , 설명비가 $15.71 \%$ 로 나타났으며 '화장품 광고 화보' 로 명명하였다.

요인 3은 고유값이 1.796, 설명비가 $11.97 \%$ 로 나타나 '브랜 드 로고' 로, 요인 4는 고유값이 1.767, 설명비가 $11.78 \%$ 로 나 타났으며 ‘제품용기 디자인’ 으로 명명하였으며, 요인 5는 고유
값이 1.707 , 설명비가 $11.38 \%$ 로 나타났으며 ‘로고색상’ 요인으 로 명명하였다(Table 4).

\section{3. 저가화장품 소비자유형 요인분석}

저가화장품 소비자유형에 대한 타당도 검증을 위해서 주성 분분석방법과 직교회전방법인 VARIMAX를 사용하여 요인분 석을 실시하였다. 본 연구에서는 $\mathrm{KMO}$ 값이 0.801 로 변수 쌍 들의 상관관계가 다른 변수에 의해 잘 설명되는 것으로 판단 할 수 있으며, 요인분석의 적합성 여부를 나타내는 Bartlett 의 구형성 검정치는 근사 카이제곱값이 1312.009 로 유의수준 이 .000으로 나타났으며, 요인분석 사용이 적합하였다. 요인 을 추출하기 위한 방법으로는 고유값이 1.0 이상인 요인에 한 하며 요인적재량이 0.4 이상인 항목들을 기준으로 설정하여 요 인수를 3 개로 결정하였다. 그 결과 요인 1은 고유값이 3.504, 설명비가 29.20\%로 나타났으며 화장품을 구입할 때 가격, 품 질, 비교, 계획이 유의하게 높아 '계획형' 요인을, 요인 2 는 고 유값이 2.875 , 설명비가 $23.95 \%$ 로 나타났으며 유행에 따라 즉 흥적 구입이 유의하게 높아 ‘트렌디형' 요인을, 요인 3은 고유 값이 1.444 , 설명비가 $12.03 \%$ 로 나타났으며 가격에 민감하여 세일기간에 구입이 유의하게 높아 ‘경제형' 요인을 명명하였다 (Table 5).

Table 4. Analysis on visual image factors of low-cost cosmetics

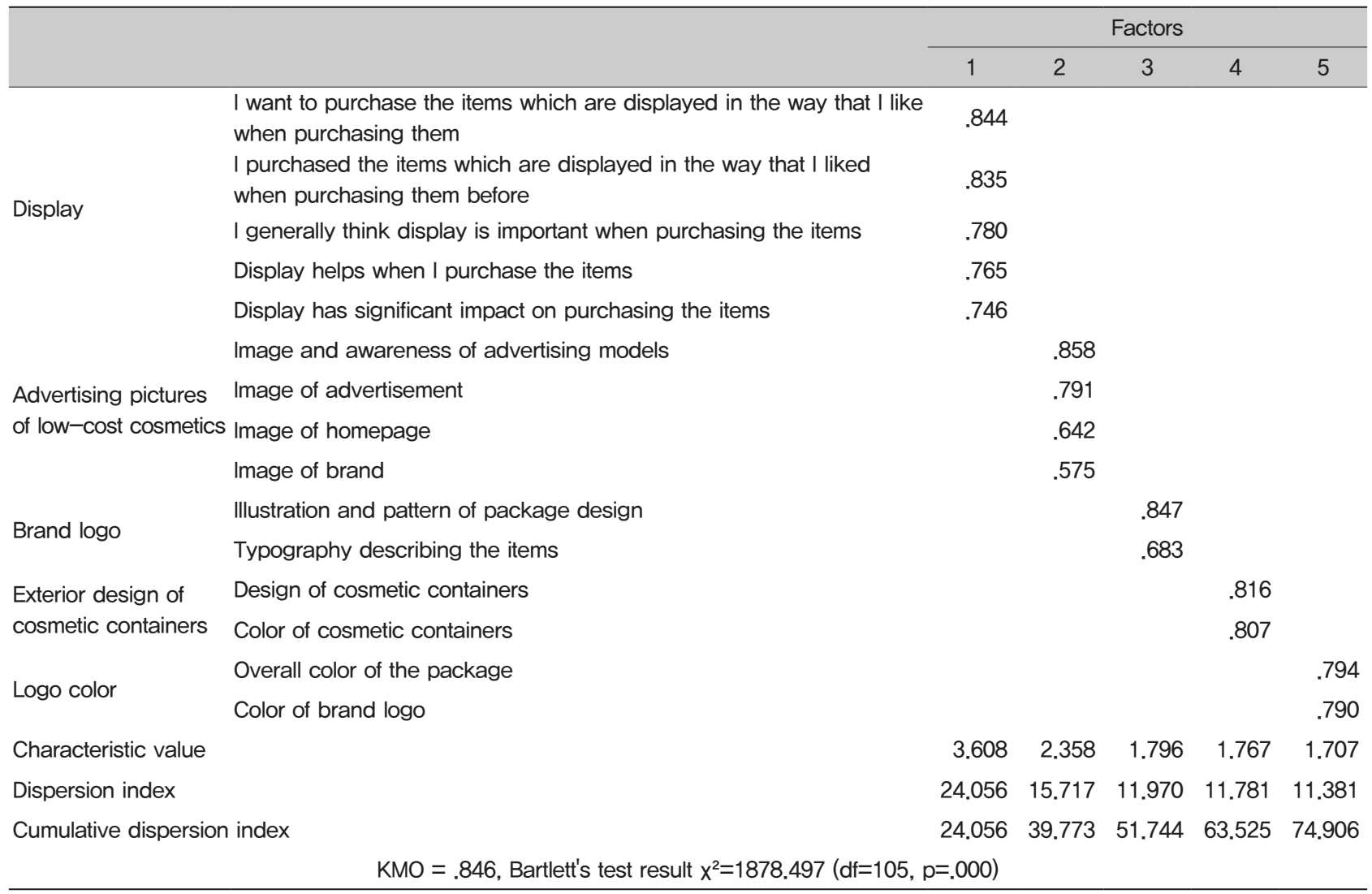




\section{4. 신뢰도 검증}

신뢰성의 측정방법은 동일한 측정도구를 동일한 대상에 시 간을 달리하여 적용결과를 비교하는 검증-재검증, 항목분할 측정치의 상관도, 내적 일관성 등이 있다. 본 연구에 사용된 측 정도구인 신뢰성은 Cronbach's 계수를 이용하여 분석하였으며 구체적인 연구결과는 다음과 같다(Table 6).

\section{5. 구매행동 특성에 따른 저가화장품 시각적 이미지의 차이}

시각적 이미지의 로고 색상과 디스플레이는 저가화장품 구매장소에 따른 차이가 유의미하였으며, 로고의 색상은 저 가화장품 구매장소가 백화점 $(\mathrm{M}=3.45)$, 화장품 전문매장
$(\mathrm{M}=3.32)$, 대형마트 $(\mathrm{M}=3.24)$, 저가 브랜드샵 $(\mathrm{M}=3.06)$, 홈쇼핑, 인터넷 쇼핑 $(\mathrm{M}=2.82)$ 순으로 백화점 구매자의 경 우 로고의 색상에 대한 요소를 가장 중요하게 생각하는 것 으로 나타났으며 $(\mathrm{p}<.05)$, 디스플레이는 저가화장품 구매장 소가 백화점 $(\mathrm{M}=3.61)$, 화장품 전문매장 $(\mathrm{M}=3.56)$, 저가 브 랜드샵 $(\mathrm{M}=3.34)$, 홈쇼핑, 인터넷 쇼핑 $(\mathrm{M}=3.22)$, 대형마트 $(\mathrm{M}=3.17)$ 순으로 디스플레이에 대한 요소를 중요하게 생각하 는 것으로 나타났다(p<.05).

또한 구매행동 특성에 따른 시각적 이미지의 저가화장품 구 입제품에 대한 차이는 없었으며 저가화장품 제품용기 디자 인과 화장품 광고 화보, 디스플레이는 저가화장품 구입 시기

Table 5. Analysis on consumer type factors of low-cost cosmetics

\begin{tabular}{|c|c|c|c|c|}
\hline & & \multicolumn{3}{|c|}{ Factors } \\
\hline & & 1 & 2 & 3 \\
\hline \multirow{6}{*}{ Planning type } & I check prices and qualities when purchasing cosmetics & .886 & & \\
\hline & I compare the cosmetics in several shops when purchasing them & .817 & & \\
\hline & $\begin{array}{l}\text { I consider the low-cost cosmetics prior to the high-cost cosmetics when purchasing } \\
\text { them }\end{array}$ & 810 & & \\
\hline & I make a plan before purchasing cosmetics that I really need & .750 & & \\
\hline & $\begin{array}{l}\text { I endeavor to collect information on cosmetics as much as possible before purchasing } \\
\text { them for satisfaction on low-cost cosmetics }\end{array}$ & .695 & & \\
\hline & I check if there is more important thing than price before purchasing cosmetics & .505 & & \\
\hline \multirow{4}{*}{ Trendy type } & I purchase makeup cosmetics depending on the trend when purchasing them & & .883 & \\
\hline & I check the trend before purchasing cosmetics & & .853 & \\
\hline & I purchase new cosmetics according to the trend when the trend is changed & & .839 & \\
\hline & I put feelings ahead of plans when purchasing cosmetics & & .526 & \\
\hline \multirow{2}{*}{ Economic type } & I am more sensitive to price than trend when purchasing cosmetics & & & .830 \\
\hline & I tend to purchase the cosmetics at cut price when purchasing cosmetics & & & .783 \\
\hline \multicolumn{2}{|c|}{ Characteristic value } & 3.504 & 2.875 & 1.444 \\
\hline \multicolumn{2}{|l|}{ Dispersion value } & 29.202 & 23.955 & 12.037 \\
\hline \multicolumn{2}{|c|}{ Cumulative dispersion value } & 29.202 & 53.157 & 65.193 \\
\hline & $\mathrm{KMO}=.801$, Bartlett's test result $\mathrm{x}^{2}=1312.009(\mathrm{df}=66, \mathrm{p}=.000)$ & & & \\
\hline
\end{tabular}

Table 6. Verification on reliability of visual image and consumer type of low-cost cosmetics

\begin{tabular}{|c|c|c|c|}
\hline & Sub-category & No. of questions & Cronbach's $\alpha$ \\
\hline & Logo color & 2 & .708 \\
\hline & Container design & 2 & .861 \\
\hline \multirow[t]{3}{*}{ Visual image of low-cost cosmetics } & Brand logo & 2 & .681 \\
\hline & Cosmetic advertising pictures & 4 & .810 \\
\hline & Display & 5 & .895 \\
\hline \multirow[t]{2}{*}{ Visual image of low-cost cosmetics } & & 15 & .895 \\
\hline & Trendy type & 4 & .805 \\
\hline \multirow[t]{3}{*}{ Consumer type } & Economic type & 2 & .527 \\
\hline & Planning type & 6 & .859 \\
\hline & Consumer type & 12 & .823 \\
\hline
\end{tabular}


에 따른 차이가 유의미하였으며 제품용기 디자인은 저가 브 랜드샵에서 화장품 구입 시기가 최근 3 개월 이내(M=3.36),

Table 7. Difference in visual image of low-cost cosmetics depending on purchasing behaviors

\begin{tabular}{|c|c|c|c|c|c|c|c|c|c|c|c|c|}
\hline & & \multirow[t]{2}{*}{$\mathrm{N}$} & \multicolumn{2}{|c|}{ Logo color } & \multicolumn{2}{|c|}{$\begin{array}{l}\text { Container } \\
\text { design }\end{array}$} & \multicolumn{2}{|c|}{$\begin{array}{c}\text { Brand } \\
\text { logo }\end{array}$} & \multicolumn{2}{|c|}{$\begin{array}{c}\text { Cosmetics } \\
\text { advertising pictures }\end{array}$} & \multicolumn{2}{|c|}{ Display } \\
\hline & & & Mean & SD & Mean & SD & Mean & SD & Mean & SD & Mean & SD \\
\hline \multirow{5}{*}{$\begin{array}{l}\text { Place of } \\
\text { purchasing }\end{array}$} & Department stores & 41 & 3.45 & .95 & 3.46 & 1.05 & 3.10 & .78 & 3.37 & .75 & 3.61 & .76 \\
\hline & Cosmetic shops & 72 & 3.32 & .81 & 3.31 & .86 & 3.09 & .69 & 3.17 & .82 & 3.56 & .72 \\
\hline & Door-to-door sales & 40 & 3.24 & .78 & 3.06 & .98 & 2.98 & .89 & 3.06 & .77 & 3.17 & .65 \\
\hline & Home shopping \& internet & 33 & 2.82 & .96 & 2.85 & .95 & 2.76 & .85 & 3.02 & .69 & 3.22 & 1.02 \\
\hline & $\begin{array}{l}\text { Low-cost cosmetics brand } \\
\text { shop }\end{array}$ & 55 & 3.06 & .73 & 3.19 & .99 & 2.93 & .84 & 3.35 & .90 & 3.34 & .81 \\
\hline \multirow[t]{2}{*}{ p (Scheffe) } & & \multicolumn{3}{|c|}{$\left..010^{*}(a, b, c, e\rangle b, c, e, d\right)$} & \multicolumn{2}{|c|}{.058} & \multicolumn{2}{|c|}{.286} & \multicolumn{2}{|c|}{.165} & \multicolumn{2}{|c|}{$.023^{*}$} \\
\hline & Makeup cosmetics (a) & 106 & 3.27 & .91 & 3.31 & .97 & 3.05 & .82 & 3.29 & .84 & 3.49 & .85 \\
\hline \multirow{3}{*}{$\begin{array}{l}\text { Cosmetics } \\
\text { purchased }\end{array}$} & Basic care cosmetics (b) & 71 & 3.14 & .84 & 3.28 & .96 & 2.96 & .75 & 3.20 & .77 & 3.46 & .75 \\
\hline & Body cosmetics (c) & 41 & 3.30 & .72 & 3.04 & 1.00 & 2.96 & .85 & 3.12 & .79 & 3.26 & .76 \\
\hline & Nail cosmetics $(\mathrm{d})$ & 23 & 2.87 & .79 & 2.78 & .80 & 2.85 & .75 & 3.03 & .77 & 3.10 & .59 \\
\hline \multirow[t]{2}{*}{$p$} & & & \multicolumn{2}{|c|}{.155} & \multicolumn{2}{|c|}{.064} & \multicolumn{2}{|c|}{.679} & \multicolumn{2}{|c|}{.458} & \multicolumn{2}{|c|}{.086} \\
\hline & In recent 1 month (a) & 69 & 3.20 & .94 & 3.27 & 1.01 & 2.97 & .77 & 3.36 & .84 & 3.54 & .84 \\
\hline \multirow{4}{*}{$\begin{array}{l}\text { Time of } \\
\text { purchasing }\end{array}$} & In recent 3 months (b) & 68 & 3.14 & .79 & 3.36 & .91 & 3.03 & .75 & 3.25 & .74 & 3.41 & .76 \\
\hline & In recent 6 months (c) & 55 & 3.41 & .83 & 3.29 & .99 & 3.11 & .84 & 3.30 & .73 & 3.54 & .75 \\
\hline & others (d) & 49 & 3.06 & .81 & 2.80 & .87 & 2.83 & .86 & 2.84 & .84 & 3.07 & .75 \\
\hline & $\mathrm{p}$ (Scheffe) & & \multicolumn{2}{|c|}{.174} & $.010 *(\mathrm{~b}$ & $c, a>a, d)$ & \multicolumn{2}{|c|}{.325} & \multicolumn{2}{|c|}{$.003^{* *}(a, c, b>d)$} & \multicolumn{2}{|c|}{$\left..006^{* *}(a, c, b\rangle b, d\right)$} \\
\hline
\end{tabular}

${ }^{* *} \mathrm{p}\left\langle .01,{ }^{* * *} \mathrm{p}\langle .001\right.$

Table 8. Impact of visual image of low-cost cosmetics on consumer type

\begin{tabular}{|c|c|c|c|c|c|c|c|c|c|}
\hline \multicolumn{2}{|c|}{ Dependent variables } & \multirow{2}{*}{$\begin{array}{l}\text { Independent variables } \\
\text { Constant }\end{array}$} & \multirow{2}{*}{$\frac{B}{.629}$} & \multirow[t]{2}{*}{$\beta$} & \multirow{2}{*}{$\frac{t}{2.065^{*}}$} & \multirow{2}{*}{$\frac{p}{.040}$} & \multirow[t]{2}{*}{$\mathrm{R}^{2}$} & \multirow[t]{2}{*}{$\operatorname{adj} R^{2}$} & \multirow[t]{2}{*}{$\mathrm{F}$} \\
\hline & & & & & & & & & \\
\hline & & Logo color & .104 & .091 & 1.245 & .214 & & & \\
\hline & & Container design & .143 & .143 & 1.883 & .061 & & & \\
\hline & Trendy & Brand logo & .029 & .024 & .325 & .746 & .202 & .185 & $11.912^{* * *}$ \\
\hline & & $\begin{array}{l}\text { Cosmetic advertising } \\
\text { pictures }\end{array}$ & .083 & .069 & .962 & .337 & & & \\
\hline & & Display & .308 & .253 & $3.485^{* *}$ & .001 & & & \\
\hline & & Constant & 2.202 & & $7.328^{* * *}$ & .000 & & & \\
\hline & & Logo color & -.167 & -.157 & $-2.029^{*}$ & .044 & & & \\
\hline & & Container design & .089 & .095 & 1.185 & .237 & & & \\
\hline \multirow[t]{9}{*}{ Consumer type } & Economic & Brand logo & -.059 & -.052 & -.662 & .509 & .106 & .087 & $5.574^{* * *}$ \\
\hline & & $\begin{array}{l}\text { Cosmetic advertising } \\
\text { pictures }\end{array}$ & .197 & .176 & $2.313^{*}$ & .022 & & & \\
\hline & & Display & .232 & .204 & $2.662^{* *}$ & .008 & & & \\
\hline & & Constant & 2.352 & & $8.360^{* * *}$ & .000 & & & \\
\hline & & Logo color & -.076 & -.078 & -.988 & .324 & & & \\
\hline & & Container design & .062 & .073 & .889 & .375 & & & \\
\hline & Planning & Brand logo & -.011 & -.010 & -.129 & .897 & .072 & .053 & $3.670^{* *}$ \\
\hline & & $\begin{array}{l}\text { Cosmetic advertising } \\
\text { pictures }\end{array}$ & .100 & .097 & 1.251 & .212 & & & \\
\hline & & Display & .204 & .196 & $2.507^{*}$ & .013 & & & \\
\hline
\end{tabular}


최근 6개월 이상 $(\mathrm{M}=3.29)$, 최근 1 개월 이내 $(\mathrm{M}=3.27)$, 기타 $(\mathrm{M}=2.80)$ 순으로 최근 3 개월 이내에 저가화장품을 구입한 구 매자의 경우 제품용기 디자인에 대한 요소를 가장 중요하게 생 각하는 것으로 나타났다( $\mathrm{p}<.05)$.

화장품 광고 화보는 저가화장품 구입 시기가 최근 1 개월 이내 $(\mathrm{M}=3.36)$, 최근 6 개월 이상 $(\mathrm{M}=3.30)$, 최근 3 개월 이내 $(\mathrm{M}=3.25)$, 기타 $(\mathrm{M}=2.84)$ 순으로 저가화장품 구입이 드문 구 매자의 경우 화장품 광고 화보에 대한 요소를 가장 중요하게 생각하지 않는 것으로 나타났다( $\mathrm{p}<.01)$.

저가 브랜드샵에서 화장품 구입 시기가 최근 1 개월 이 내 $(\mathrm{M}=3.54)$, 최근 6 개월 이상 $(\mathrm{M}=3.54)$, 최근 3 개월 이내 $(\mathrm{M}=3.41)$, 기타 $(\mathrm{M}=3.07)$ 순으로 저가화장품 구입이 드문 구 매자의 경우 디스플레이에 대한 요소를 가장 중요하게 생각하 지 않는 것으로 나타났다(p<.01) (Table 7).

\section{6. 저가화장품의 시각적 이미지가 소비자유형에 미치는 영향}

저가화장품의 시각적 이미지가 화장품 소비자유형의 트렌 디형에 미치는 영향을 알아보기 위하여 다중회귀분석을 실시 한 결과, $R^{2}=0.202$ 로 전체 변동의 $20.2 \%$ 로 회귀모형을 설명 하고 있음을 알 수 있다. 변수간 다중공선성을 진단하기 위하 여 분산 팽창계수(VIF: variable inflation factor)와 허용치 (tolerance)를 본 결과 본 분석에서 변수들의 VIF값은 모두 10 이하였고, 허용치는 0.1 보다 크게 나타나 다중공선성의 문제 는 발생하지 않는 것으로 볼 수 있다. 모형에 대한 분산분석 결 과 추정된 모형은 유의한 것을 알 수 있었으며( $\mathrm{p}<.001)$, 화장 품 시각적 이미지의 디스플레이 $(\beta=.253, \mathrm{p}<.01)$ 만 트렌디형 에 유의미한 영향력을 미치는 것으로 나타났다. 따라서 저가 화장품의 디스플레이를 중요하게 생각할수록 트렌디형이 높은 것을 알 수 있다. 화장품의 시각적 이미지가 소비자유형의 경 제형에 미치는 영향을 알아보기 위하여 다중회귀분석을 실시 한 결과, $\mathrm{R}^{2}=0.106$ 으로 전체 변동의 $10.6 \%$ 로 회귀모형을 설 명하고 있음을 알 수 있으며, 모형에 대한 분산분석 결과 추정 된 모형은 유의한 것을 알 수 있었으며(p<.001), 저가화장품 시각적 이미지의 디스플레이 $(\beta=.204, p<.01)$, 화장품 광고 화 보( $\beta=.176, \mathrm{p}<.05)$, 로고의 색상 $(\beta=-.157, \mathrm{p}<.05)$ 순으로 경제형에 유의미한 영향력을 미치는 것으로 나타났다. 이는 저 가화장품의 디스플레이와 화장품 광고 화보를 중요하게 생각 할수록, 로고의 색상을 중요하게 생각하지 않을수록 경제형이 높은 것을 의미한다.

저가화장품의 시각적 이미지가 소비자유형의 계획형에 미 치는 영향을 알아보기 위하여 다중회귀분석을 실시한 결과, $\mathrm{R}^{2}=0.072$ 로 전체 변동의 $7.2 \%$ 로 회귀모형을 설명하고 있음을 알 수 있으며. 모형에 대한 분산분석 결과 추정된 모형은 유의 한 것을 알 수 있었으며(p<.01), 저가화장품 시각적 이미지의
디스플레이( $\beta=.196, p<.05)$ 만 계획형에 유의미한 영향력을 미 치는 것으로 나타났다(Table 8).

\section{Conclusion}

본 연구는 저가화장품이 보여주는 시각적 이미지에 대해 알 아보고 이에 따른 소비자유형과 구매행동에 미치는 영향을 알 아보고자 하였으며 연구 결과는 다음과 같다.

첫째, 시각적 이미지 요인, 소비자유형을 요인분석 한 결과, 시각적 이미지는 로고의 색상, 제품용기 디자인, 브랜드 로고, 화장품 광고 화보, 디스플레이의 다섯 가지 요인이 도출되었고 소비자유형은 트렌디형, 경제형, 계획형의 세가지 요인이 도출 되었다.

둘째, 구매행동에 따른 저가화장품 시각적 이미지의 차이를 알아본 결과 저가화장품 시각적 이미지의 로고 색상과 디스플 레이는 화장품 구매장소에 따른 차이가 유의미하였으며, 저가 화장품 구입제품에 따른 차이는 없었으며, 제품용기 디자인과 화장품 광고 화보, 디스플레이는 저가화장품 구입시기에 따른 유의미한 차이가 나타났다. 이는 저가화장품을 구입할 때 같은 제품을 구입하더라도 매장의 분위기에 따라 시각적 이미지의 중요도를 다르게 생각하는 것으로 보여진다.

셋째, 저가화장품의 시각적 이미지가 저가화장품 소비자유 형에 미치는 영향을 살펴본 결과 부분적으로 유의미한 영향을 미치는 것으로 나타났다. 저가화장품의 디스플레이를 중요하게 생각할수록 트렌디형과 계획형이 높았으며, 저가화장품의 디스 플레이, 화장품 광고화보, 로고 색상 순으로 경제형에 유의미 한 영향력을 미치는 것으로 나타났다. 경제형 소비자의 경우 합 리적이고 계획적인 쇼핑을 추구하므로 어떠한 제품을 구입하기 전 트렌디형이나 계획형보다 가격 및 품질뿐만 아니라 시각적 이미지를 분석하고 자신에게 맞는 제품을 선호하는 것으로 보 인다.

이는 시각적 이미지에 따라 경제형, 트렌디형, 계획형에 미치 는 영향의 차이를 보이고 있다. 따라서 소비자유형에 따른 잠재 고객들의 구매욕구 필요조건을 구별하는 시장 세분화의 기준 역할을 하고 있는 것으로 사료되며 마케팅 전략의 중요한 변수 임을 알 수 있다. 또한 2013년도 선행연구(Han et al., 2013) 의 결과에서 중저가화장품의 패키지 디자인이 시각적으로 아름 답다고 느끼면 브랜드 이미지와 상관없이 바로 구매한다는 연 구 결과가 있다. 이러한 결과로 볼 때 브랜드 이미지와 제품 이 미지 그리고 제품 구매를 위한 시각적 요소로 기업에서는 가격 경쟁력 및 품질향상 이외에 마케팅전략이 필요하다는 것을 시 사한다. 따라서 브랜드의 시각적 이미지 개발을 위한 지속적인 노력과 소비자의 구매행동을 충분히 파악하여 전략적인 마케팅 
과제를 안고 있다. 또한 시각적 이미지를 통해 지속적으로 보 여줄 수 있는 브랜드 이미지를 고려하여 제품 또는 고객 동선에 맞추어 디스플레이 공간을 마련해야 할 것으로 사료된다. 이러 한 결과를 바탕으로 저가화장품의 시각적 이미지는 소비자유형 과 구매행동에 긍정적인 영향을 준다는 것을 인지하고 저가화 장품의 획일화된 제품 품질 및 가격 경쟁력뿐만 아니라 독특한 개성과 특징을 가미하여 화장품 산업에서 저가화장품시장에서 의 마케팅 전략 이미지로 보여지는 디스플레이, 화장품 광고 화 보 등의 차별화 전략을 구축할 것을 제안한다.

본 연구의 제한점은 다음과 같다.

저가화장품의 구매행동 문항이 명목척도 3 문항으로 국한되 어 일반적인 구매행동을 확인하기에는 한계점이 있다고 할 수 있다.

이와 같은 제한점을 고려하여 다양한 연령대를 표본 집단으 로 확대하여 일반화된 결과도출의 필요성이 있으며 구매행동 특성의 도구를 재개발 하여 반복 연구의 필요가 있을 것으로 사 료되며 이를 통해 시각적 이미지 요인을 고려하여 소비자유형 별로 구매행동에 대한 비교분석의 포괄적인 연구가 계속되길 기대한다.

\section{Acknowledgements}

This paper is funded by the 2015 Research Funds of Suwon Women's University.

\section{References}

Ahn SY, Shin SY. Eye shadow's color characteristics of Korea's low-Price cosmetic brands. Journal of the Korean Beauty Art Society, 6: 27-34, 2012.

Chung SY, Kim JS. Influence of perceived quality on brand image and brand loyalty in the low-priced cosmetic industry. Journal of Industrial Relations, 34: 199-216, 2009.

Han DY. An effect of the PB products attribute of the large-sized discount stores on the consumer attitude and the purchase behavior. Journal of Digital Convergence, 13: 51-60, 2015.

Han JM, Lee MA, Kang HS. The effect of package design of domestic low price cosmetic brand on brand loyalty: focusing on dual paths of emotional image and functional image. Design Convergence Study, 12: 129-142, 2013.

Hwang JY. A study on the characteristics of packaging design according to the trend of cosmetics industry. A Journal of Brand Design Assocation of Korea, 20: 109-120, 2012.

Hyun JH, Choo TG. A study on purchasing behaviors of budget-priced cosmetic. Fashion \& Textile Research Journal, 7: 617-623, 2005.

Hyun JH, Choo TG. Purchasing behaviors of budgetpriced cosmetics according to the shopping orientation and demographics. Fashion \& Textile Research Journal, 7: 624-632, 2005.

Jeon JO, Park HH. A study on the development of fashion VMD cognition measurement instrument. Journal of Marketing Management Research, 10: 117-139, 2005.

Kim CJ, Park JS. Consumer's emotional responses to cosmetic packaging design. A Journal of Brand Design Assocation of Korea, 34: 79-90, 2015.

Kim JD. A study on the actual condition of using lowpriced cosmetics and on the purchasing behavior in female undergraduates. Journal of the Society of Cosmetic Scientists of Korea, 37: 177-189, 2011.

Kim MS. A study on the effect of the visual factors of the package design on the purchase desires of the consumers: focusing on the B2B food products. A Journal of Brand Design Assocation of Korea, 10: 257-270, 2012.

Kim SE, Chung MS. The effect of emotional experience with korea's low-price cosmetic brands on brand relationship. The Research Journal of the Costume Culture, 19: 565-578, 2011.

Kim SW, Roh YL. The use and satisfaction of low price cosmetics among female college students. Journal of the Korean Home Economics Association, 46: 107117, 2008.

Lee JM, Hwang JS. The effect of experiential marketing on the brand equity of low-priced cosmetics brands. Journal of the Korean Society of Costume, 60: 100117, 2010.

Lee S, Jeong HY, Lee JM. A case analysis on the color utilization for the brand identity of low-priced cosmetics. Journal of the Korean Beauty Art Society, 6: 165-174, 2012.

Lee TS, Yun CJ, Sheen YS. The effects of cosmetics brand image on consumers value, brand trust and customer 
commitment. Journal of Investigative Dermatology, 11: 259-267, 2015.

Lee YJ, Shin SY. Visual image evaluation criteria of domestic and international cosmetics brands. Journal of the Korean Society of Design Culture, 21: 537$550,2015$.

Park EH, Ku YS. Cosmetics behavior and purchasing behavior according to female cosmetics consumer' s shopping propensity typology. Journal of Fashion Business, 15: 28-42, 2011.

Ryu SJ. An exploratory study of the relationship between cosmetic brand image and loyalty as consumer types: focused on low-priced cosmetics. The Research Journal of the Costume Culture, 16: 1099-1110,
2008.

Sim EK, Lee HS. A study on fermented cosmetic purchasing behaviors and consumption values of college girls in their 20s. Korean Journal of Aesthetics and Cosmetology, 13: 721-728, 2015.

Song TI. A comparative study on buying behavior on cosmetics of low-price brand and the beauty care behavior as the life styles of students in high school. Journal of the Korean Society of Design Culture, 21: 309-323, 2015.

Sun JH, Yoo TS. Cosmetics purchasing behavior according to lifestyle types of discount store consumers. Journal of the Korean Society of Costume, 53: 75-86, 2003. 


\section{국문초록}

\section{저가화장품 시각적 이미지가 소비자유형과 구매행동에 미치는 영향}

이상은

수원여자대학교 미용예술과, 경기도 수원시, 한국

목적: 본 연구는 저가화장품의 시각적 이미지 매개변수가 소비자유형과 구매행동에 미치는 특성 차이를 밝히고자 한다.

방법: 저가화장품을 사용한 경험이 있는 성인여성을 대상으로 편의 표집하였다. 타당도 검증을 위하여 요인분석을 실시하고 oneway ANOVA, Scheffe's multiple range test, 다중회귀분석을 실시하였다.

결과: 시각적 이미지는 로고의 색상, 제품용기 디자인, 브랜드 로고, 화장품 광고 화보, 디스플레이의 다섯가지 요인이 도출되었고 소비자유형은 트랜디형, 경제형, 계획형의 세가지 요인이 도출되었다. 시각적 이미지의 로고 색상과 디스플레이는 화장품 구매장소 와 구입시기에 따른 유의미한 차이가 나타났으며, 소비자유형에 따라 부분적으로 유의미한 영향을 미치는 것으로 나타났다.

결론: 저가화장품의 시각적 이미지가 소비자유형과 구매행동에 긍정적인 영향을 준다는 것을 인지하고 저가화장품의 획일화된 제 품 품질 및 가격 경쟁력뿐만 아니라 독특한 개성의 시각적 이미지를 마케팅 차별화 전략으로 구축할 것을 제안한다.

핵심어: 시각적 이미지, 저가화장품, 소비자유형, 구매행동, 화장품 산업

본 연구는 2015년도 수원여자대학교 순수 연구과제 지원에 의해 수행되었음.

\section{참고문헌}

김미선. 패키지 디자인의 시각적 요소가 소비자 구매의도에 미치는 영향. 브랜드디자인학연구, 10: 257-270, 2012.

김성은, 정명선. 국내 저가 화장품 브랜드에 대한 감성적 경험이 브랜드 관계에 미치는 영향. 복식문화연구, 19: 565-578, 2011. 김시월, 노영래. 저가화장품 사용실태와 구매만족도-여대생을을 중심으로-. 대한가정학회지, 46: 107-117, 2008. 김주덕. 여대생들의 저가화장품에 대한 사용실태 및 구매행동에 관한연구. 대한화장품학회지, 37: 177-189, 2011. 김찬주, 박지선. 화장품 유형별 패키지 디자인에 대한 소비자 감성 반응 연구. 브랜드디자인학연구, 13: 79-90, 2015. 류세자. 소비자유형별 화장품 브랜드 이미지와 충성도와의 관계에 대한 탐색적 연구-저가 화장품 시장을 중심으로-. 복식문화연 구, 16: 1099-1110, 2008.

박은희, 구양숙. 화장품 소비자의 쇼핑성향 유형에 따른 화장행동 및 구매행동. 패션비즈니스, 15: 28-42, 2011. 선정희, 유태순. 대형할인점 소비자의 라이프스타일 유형에 따른 화장품 구매행동. 한국복식학회지, 53: 75-86, 2003. 송태임. 고등학생의 일반적 생활양식 유형에 따른 저가 브랜드 화장품 구매행동과 뷰티관리 행동 비교 연구. 한국디자인문화학회 지, 21: 309-323, 2015.

심은경, 이현실. 20대 여대생의 발효화장품 구매특성과 소비가치에 관한 연구. 대한피부미용학회지, 13: 721-728, 2015. 안서영, 신세영. 국내 저가화장품 브랜드의 아이새도우 색채특성. 한국미용예술학회지, 6: 27-34, 2012.

이유정, 신세영. 국내외 화장품 브랜드의 시각적 이미지 평가기준. 한국디자인문화학회지, 21: 537-550, 2015.

이솔, 정현영, 이정민. 저가화장품 브랜드 아이덴티티와 컬러 활용사례 분석. 한국미용예술학회지, 6: 165-174, 2012.

이정민, 황진숙. 저가화장품 브랜드 체험 제공수단과 체험마케팅 유형이 브랜드자산에 미치는 영향. 한국복식학회지, 60: 100117, 2010.

이택성, 윤찬주, 신영식. 화장품 브랜드 이미지가 소비자 가치와 브랜드 신뢰, 고객몰입에 미치는 영향. 대한미용학회지, 11: 259-

267, 2015.

전중옥, 박현희. 패션 VMD 인지 측정 도구 개발을 위한 연구. 마케팅관리연구, 10: 117-139, 2005. 
정선영, 김준석. 지각된 품질이 브랜드 이미지와 충성도에 미치는 영향에 관한 연구-저가화장품을 중심으로-. 산연논총, 34 : 199-216, 2009.

한동여. 대형할인점 PB제품 속성이 소비자의 태도와 구매행동에 미치는 영향. 디지털융복합연구, 13: 51-60, 2015.

한정민, 이미아, 강혜승. 국내 중저가화장품 패키지의 디자인 특성이 브랜드 충성도에 미치는 영향-감성적 이미지와 기능적 이미지 의 이중경로를 중심으로-. 디자인융복합연구, 12: 129-142, 2013.

현정희, 추태귀. 쇼핑성향과 인구통계적 변인에 따른 초저가 화장품의 구매행동. 한국의류산업학회지, 7: 624-632, 2005. 현정희, 추태귀. 초저가 화장품의 구매행동에 관한 연구. 한국의류산업학회지, 7: 617-623, 2005.

황지영. 화장품 산업동향에 따른 패키지 디자인의 특성연구. 브랜드디자인학연구, 20: 109-120, 2012. 


\section{中文摘要}

\section{低廉化妆品的视觉效应对消费者类型和购买行为的影响}

\section{李相恩}

水原女子大学校 美容艺术科, 京畿道水原市, 韩国

目的: 阐明低廉化妆品的视觉效应对消费者类型和购买行为影响的差异。

方法: 对已用过低廉化妆品经验的成人女性采用便利抽样的方式选择研究对象。为了妥当性, 采用因子分析、单因素方差分 析、Scheffe's multiple range test和多元回归等分析方法进行研究。

结果: 视觉效应在商标颜色、产品容器设计、品牌商标、化妆品广告、展览等五个方面突出。而消费者类型在最新流行、经济 型、计划型等三个方面比较突出。

结论: 研究结果显示出低廉化妆品的视觉效应对消费者类型及购买行为产生积极的影响, 并且需要对低廉化妆品建立品质保 证, 价格竞争力以及独特视觉效应的差异化营销策略。

关键词: 视觉效应, 低廉化妆品, 消费者类型, 购买行为, 化妆品产业 